\title{
Management of Complicated Crown Fracture: Tooth Fragment Re-Attachment as A Single Visit Procedure with Crown Lengthening by Diode Laser: An Interdisciplinary Case Series.
}

\author{
${ }^{1}$ Dr.Thillainayagam, ${ }^{2}$ Dr.S.Karthikeyan, ${ }^{3}$ Dr.K.Sivaranjani, \\ ${ }^{1}$ Professor, Head of the Department, Department of Conservative Dentistry \& Endodontics, Adhiparasakthi \\ Dental College \& Hospital, Melmaruvathur. \\ ${ }^{2}$ Senior Lecturer, Department of Conservative Dentistry \& Endodontics Adhiparasakthi Dental College \& \\ Hospital, Melmaruvathur. \\ ${ }^{3}$ Senior Lecturer, Department of Periodontics, Adhiparasakthi Dental College \& Hospital, Melmaruvathur.
}

\section{Introduction}

Coronal fracture of anterior teeth is most common traumatic injury of permanent dentition1.2. The upper central incisors are the teeth most frequently affected by this type of dental injury3. The traumatic incident related to central incisor is because of buccal positioning of teeth4.

Dental injuries usually affect only a single tooth. However, certain trauma types such as sports injuries \& automobile accidents involving multiple tooth injuries5. Treatment of crown fractures depends on many factors involving extent of fracture whether it involves part of root, amount of biologic width, involvement of alveolar bone fracture, fracture pattern, occlusion, aesthetics, presence or absence of fractured tooth fragment and its condition, prognosis of the condition6-8.

Re-attachment of tooth fragment is one of the best options for managing coronal tooth fracture when there is no or minimum violation of biologic width9. When there is invasion of biologic width or substantial associated periodontal injury, restorative management of coronal fragment should follow proper management of these associated issues.

The main advantages related to fractured toothe re-attachment are conservative, Aesthetics, costeffective and it is an acceptable alternative to restoration of fractured tooth with resin based composite or full coverage crown10-12. However in such cases, esthetics may become an important issue as pulpless teeth lost part of their translucency and brightness.

There are few experimental models have proved that, the limit of fractured strength remains same when $90 \%$ of the original tooth structure is maintained. According to Rais\&pusnam, the minimum strength of fractured teeth is not known, even many authors claims 50\% strength seems to be sufficient.

This article reports two clinical case reports of fractured tooth re-attachment treated successfully with crown lengthening by Diode laser.

\section{Case 1}

An 35 year old male patient reported to the outpatient Department of Conservative Dentistry \&Endodontics, Adhiparasakthi Dental College and Hospital ,Tamilnadu, India with chief complaint of broken upper front tooth region due to trauma which occurred two days back.

On intra oral examination, 21 had fractured completely with the fracture line present subgingivally. However, the fractured segment was still attached, but mobile, the mobility was evident on labio-palatal direction. On radiographic examination, the fracture line was 1-2 $\mathrm{mm}$ below CEJ.Pulpal status,periodontal conditions of adjacent tooth was checked. In 21 the tooth was found non-vital and root canal treatment completed in single visit.

There was no evidence of periodontal and pulpal trauma in adjacent teeth. They were vital. The patient expressed the desire of maintaining the tooth. So, considering the various treatment options available,we are decided to carry out endodontic treatment followed by cementation of fiber post and re-attachment of fractured tooth using self-adhesive resins. The treatment plan was explained to patient, and the patient was accepted for the treatment.

Local anaesthesia was administered and the mobile fractured segment was separated and removed. It was then placed on $0.9 \%$ normal saline to prevent dehydration. The tooth was isolated and single visit root canal treatment was done by standard step back technique for biomechanical preparation and the canal was obturated with No.70 GP as an sectional obturation method in $4 \mathrm{~mm}$ apical part of canal to maintain the apical seal.

After the endodontic treatment over,post space was prepared using the drill( and the patient Is sent to the department of periodontics for crown lengthening on the lingual aspect. Fiber post was selected corresponding to the size of the drill used, and fit of the fiber post was 
examinedradiographically.Crown lengthening was done on the lingual aspect of incisors by lasers. Accurate fit of the crown was checked after crown lengthening.

The fractured segment was re-attached, ensuring the tooth was well positioned and in good contact. A flowablecomposite was used to adhere with the post of the fragment of canal for 30 seconds using light cure unit 3M ESPE.Occlusion was checked using articulating paper.No interferences was noted ,excess material was removed and restoration margins were finished with series of polishing burs and the tooth was polished to high luster using aluminium disks.

The patient was instructed to avoid loading the anterior teeth. Immediate postoperative clinical assessment presented good esthetics and good occlusion while radiographic examination showed stable reattachments and good periodontal health.Follow up appointment of 1 week, 1 month and 3 months clinical examination revealed which showed normal aspects of toothand supporting structures.

\section{Case Report 2}

A 42 year old male patient reported to the Department of Conservative Dentistry and Endodontics,APDCH,Melmaruvathur,Tamilnadu, with chief complaints of fractured upper anterior teeth due to impact force of sugarcane bite.

On intraoral examination, 22 was fractured completely with fractured line present Subgingivally with labially and palatally.But,the fractured segments was still attached, but mobile, the mobility was evident on labiopalatal direction. Various treatment procedure explained to the patient. Among all the various treatment options, patient desire to reattachment of own fractured teeth.

Patient referred to Department of Periodontics for elevation of flap using laser. Flap was elevated and fit of fractured segment checked. Fractured segment re-attached using fiber post. Post-operative radiograph taken and fit of the fractured segments confirmed.

Patient evaluated after aweek, 1month, 3 months which showed normal aspects of tooth and supporting structures.

\section{Discussion}

With advancement in dental bonding technology, it is now possible to achieve excellent results with reattachment of dislocated tooth fragments provided that the biologic factors,materials and techniques are logically assessed and managed. The use of natural tooth substance clearly eliminates the problems of differential wear of restorative material, unmatched shades and difficulty of contour and texture reproduction associated with other techniques. Treatment plan can be made after evaluation of the periodontal, endodontic, coronal and occlusal status 13 .Other factors that might influence the choice of technique include the need for endodontic therapy, extension of fracture, quality of fit between fragments and the fracture pattern.

Badami and associates 14 have shown neither the bevel nor the material used could obtain the original fracture resistance of the tooth. Specimens prepared with chamfer and bonded had a fracture resistance of 40$60 \%$, with internal dentin groove and over contour it reached around $90 \%$.A simple reattachment procedure as in the first case is indicated, since bevel with flowable composite improves fracture strength recovery. The resistance of the fracture segment can be directly proportional to the surface area of adhesion.

Most of the 5th generation bonding agents increased the fracture resistance of reattached coronal fragments when used with conjunction with unfilled resin. Extensively fractured fragments have to be restored with conjunction with a resin. The highest fracture resistance was obtained by chemically cured composite followed by light cured and resin cement and least by only dentin bonding agent 15 .The pulp chamber was used for increasing the surface area for composite bonding and without the use of post. Amir et al in 198616 showed when endodontic therapy is required, the space provided by pulp chamber may be used as an inner reinforcement, thus avoiding any excess preparation of teeth.

\section{Conclusion}

According to our clinical evaluation, the restoration of a fractured crown using the adhesive reattachment is the optimal treatment for an enamel-dentin fracture when the tooth fragment is available, intact and well preserved. The clinical results appear to be positive and they show that this technique is easy to perform and standardize, inexpensive, and that it allows both functional and aesthetic recovery. In fact, the reattachment technique helps avoid the silicon matrix that is required to model the palatal surface properly to create a base for the subsequent composite layering. When compared to more aggressive prosthetic techniques like crowns and veneers, the reattachment technique is both conservative and aesthetic.

Using this treatment procedure it is possible to achieve long-term retention and good mechanical resistance of the toothfragment complex. Our clinical experiences, in accordance with literature data, prove that when the fragment is quickly reattached it is possible to preserve pulp vitality. The quality of the adhesion turned out to be suitable although an ultraconservative technique was preferred without any type of preparation 
and only with the use of the bonding method. In any case, it was possible to perform the reattachment again with positive outcomes.

\section{References}

[1]. Dietschi D, Jacoby T, Dietschi JM, Schatz JP. Treatment of traumatic injuries in the front teeth: restorative aspects in crown fractures. Pract Periodontics Aesthet Dent 2000;12(8):751-8, quiz 760

[2]. Hamilton FA, Hill FJ, Holloway PJ. An investigation of dento-alveolar trauma and its treatment in an adolescent population. Part 1: the prevalence and incidence of injuries and the extent and adequacy of treatment received. Br Dent J 1997;182:91-5.

[3]. Eden E, Yanar SC, Sönmez Ş. Reattachmnet of subgingivally fractured central incisor with an open apex. Dent Traumatol 2007;23:184-9.

[4]. Pusman E, Cehreli ZC, Altay N, Unver B, Saracbasi O, Ozgun G. Fracture resistance of tooth fragment reattachment: Effects of different preparation techniques and adhesive materials. Dent Traumatol 2010;26:9-15.

[5]. Demarco FF, De Moura FR, Tarquinio SB, Lima FG. Reattachment using a fragment from an extracted tooth to treat complicated coronal fracture. Dent Traumatol 2008;24:157-61.

[6]. Olsburgh S, Jacoby T, Krejci I. Crown fractures in the permanent dentition: pulpal and restorative considerations. Dent Traumatol 2002;18(3):103-15.

[7]. Reis A, Francci C, Loguercio AD, et al. Re-attachment of anterior fractured teeth: fracture strength using different techniques. Oper Dent 2001;26(3):287-94.

[8]. Andreasen FM, Noren JG, Andreasen JO, et al. Long term survival of fragment bonding in the treatment of fractured crowns. Quintessence Int 1995;26:669-81.

[9]. 9.Baratieri LN, Ritter AV, Junior SM, Filho JCM. Tooth fragment reattachment: an alternative for restoration of fractured anterior teeth. PractPeriodontAesthet Dent 1998;10: 115-27.

[10]. El-Askary FS, Ghalab OH, Eldemerdash FH et al. Reattachment of a severely traumatized maxillary central incisor, one-year clinical evaluation: a case report. J Adhes Dent 2006;8(5):343-9.

[11]. Reis A, Loguercio AD, Kraul A, Matson E. Reattachment of fractured teeth: a review of literature regarding techniques and materials. Oper Dent 2004;29(2):226-33.

[12]. Rappelli G, Massaccesi C, Putignano A. Clinical procedures for the immediate reattachment of a tooth fragment. Dent Traumatol 2002;18(5):281-4.

[13]. Chu FCS, Yim TM, Wei SHY. Clinical considerations for reattachment of fractured tooth fragments. Quintessence Int 2000;31:38591

[14]. Badami AA, Dunne SM, Scheer B. An in vitro investigation into the shear bond strengths of two dentine bonding agents used in the reattachment of incisal edge fragments. Endod Dent Traumatol 1995;11:129-35

[15]. Reis A, Loguercio AD, Kraul A, Matson EL. Reattachment of fractured teeth: A review of literature regarding techniques and materials. Oper Dent 2004; 29:226-33.

[16]. Amir E, Bar-Gil B, Sarnat H. Restoration of fractured immature maxillary central incisors using the crown fragments. Paed Dent $1986 ; 8: 285-88$

TABLE-1

\begin{tabular}{|c|c|c|}
\hline DEMOGRAPHIC & \multicolumn{2}{|c|}{ TOTAL PARTICIPANTS- 480} \\
\hline \multirow[b]{2}{*}{ GENDER } & Male & $261 \quad(54 \%)$ \\
\hline & Female & $219(46 \%)$ \\
\hline \multirow{4}{*}{ AGE (IN YEARS) } & 20 and $<20$ years & $65 \quad(14 \%)$ \\
\hline & 21 to 40 & $207(43 \%)$ \\
\hline & 41 to 60 & $146(30 \%)$ \\
\hline & 61 to 80 & $62 \quad(13 \%)$ \\
\hline \multirow{4}{*}{ EDUCATION } & Upto high school level & $136(28 \%)$ \\
\hline & Upto college & $190(40 \%)$ \\
\hline & Upto university and above & $109(23 \%)$ \\
\hline & Uneducated & $45 \quad(9 \%)$ \\
\hline \multirow{6}{*}{ QUALIFICATION } & Student & $(14 \%)$ \\
\hline & Unemployed & $(12 \%)$ \\
\hline & Housewife & $(14 \%)$ \\
\hline & Unskilled & $(13 \%)$ \\
\hline & Professional & $113(23 \%)$ \\
\hline & Business & $116(24 \%)$ \\
\hline
\end{tabular}




\begin{tabular}{|c|c|c|}
\hline 3 & $\begin{array}{l}\text { Would you be Content with removable placement /denture } \\
\text { as relacement for missing tooth? }\end{array}$ & \\
\hline a) & Yes & 262 \\
\hline b) & No & 248 \\
\hline 4 & Have you Heard of implant treatement? & \\
\hline a) & Yes & 357 \\
\hline b) & No & 153 \\
\hline 5 & $\begin{array}{l}\text { Do you know that implants can be used for replacement } \\
\text { of missing teeth? }\end{array}$ & \\
\hline a) & Yes & 304 \\
\hline b) & No & 206 \\
\hline 6 & How well informed do you feel about about implant? & \\
\hline a) & Very well & 41 \\
\hline b) & Well & 114 \\
\hline c) & Moderately well & 142 \\
\hline d) & Poorly & 203 \\
\hline e) & Not at all & 10 \\
\hline 7 & Would you like to get implant treatment if needed? & \\
\hline a) & Yes & 356 \\
\hline b) & Not at all & 154 \\
\hline 8 & What do you Personally think of dental implant treatment? & \\
\hline a) & Opted if needed & 371 \\
\hline b) & Opted for other alternatives & 139 \\
\hline 9 & Do you think Implant needs special care and hygiene? & \\
\hline a) & No & 192 \\
\hline b) & No less than natural teeth & 91 \\
\hline c) & Yes need more care & 227 \\
\hline 10 & Like to know more about dental implants? & \\
\hline a) & Yes & 407 \\
\hline b) & No & 103 \\
\hline 11 & Where do you think dental implants are placed? & \\
\hline a) & Jaw bone & 332 \\
\hline b) & Gums & 63 \\
\hline c) & Neighboring teeth & 48 \\
\hline d) & Don't know & 67 \\
\hline
\end{tabular}


Management Of Complicated Crown Fracture: Tooth Fragment Re-Attachment As A Single Visit...

\begin{tabular}{|c|c|c|}
\hline 12 & How long do you thinka Dental implant lasts? & \\
\hline a) & $<5 \mathrm{yr}$ & 208 \\
\hline b) & $<10$ & 166 \\
\hline c) & Upto 20 & 51 \\
\hline d) & Life time & 85 \\
\hline 13 & Biggest advantage of implant & \\
\hline a) & Fixed replacement & 141 \\
\hline b) & Looks better & 242 \\
\hline c) & Good in function & 91 \\
\hline d) & Avoids grinding of natural teeth & 36 \\
\hline 14 & Biggest disadvantage & \\
\hline a) & High cost & 284 \\
\hline b) & Need of surgery & 142 \\
\hline c) & Long treatment time & 84 \\
\hline 15 & Reason for failure of dental implants? & \\
\hline a) & Dentist & 130 \\
\hline b) & Patient & 82 \\
\hline c) & Poor oral hygiene & 165 \\
\hline d) & Allergic/Incompatibility & 133 \\
\hline 16 & $\begin{array}{l}\text { How do you think the treatement charges which are involved } \\
\text { In this procedure? }\end{array}$ & \\
\hline a) & Affordable & 176 \\
\hline b) & Non affordable & 334 \\
\hline 17 & $\begin{array}{l}\text { What in your opinion majority contributes to the cost of } \\
\text { Dental implants? }\end{array}$ & \\
\hline a) & Cost of dental implants & 277 \\
\hline b) & Cost of surgery & 127 \\
\hline c) & Company supplying implant & 53 \\
\hline d) & Dentist & 53 \\
\hline 18 & Who in your Opinion should opt for Dental implant? & \\
\hline a) & Implants are good for every one & 239 \\
\hline b) & Expensive only for rich & 271 \\
\hline
\end{tabular}

